\title{
A Simplified Mathematical Model for Calculating the Thermal Efficiency of a Wood Pellets-Fired Industrial Boiler on the Basis of Error Analysis Method
}

\author{
Xiaozhou Liu ${ }^{1,3}$, Ruiyu $\mathrm{Li}^{2}$, *, Chunhui $\mathrm{He}^{2}$, Yuesheng $\mathrm{Li}^{2}$, Hongwei $\mathrm{Wu}^{3}$ \\ ${ }^{1}$ School of Material \& Energy, Guangdong University of Technology, Guangzhou, PR China \\ ${ }^{2}$ Guangdong Special Equipment Inspection and Research Institute Shunde Inspection Institute, Foshan, PR China \\ ${ }^{3}$ School of Engineering and Technology, University of Hertfordshire, Hatfield, United Kingdom \\ Email address: \\ liuzhang852@163.com (Xiaozhou Liu), liruiyu6741297@126.com (Ruiyu Li), hewanglan.liu@nibq.org (Chunhui He), \\ gzlys@139.com (Yuesheng Li), h.wu6@herts.ac.uk (Hongwei Wu) \\ ${ }^{*}$ Corresponding author
}

\section{To cite this article:}

Xiaozhou Liu, Ruiyu Li, Chunhui He, Yuesheng Li, Hongwei Wu. A Simplified Mathematical Model for Calculating the Thermal Efficiency of a Wood Pellets-Fired Industrial Boiler on the Basis of Error Analysis Method. Science Journal of Energy Engineering.

Vol. 6, No. 2, 2018, pp. 37-41. doi: 10.11648/j.sjee.20180602.12

Received: August 16, 2018; Accepted: September 25, 2018; Published: October 18, 2018

\begin{abstract}
The traditional calculation method of industrial boiler thermal efficiency needs to input many parameters, which leads to a lot of complicated calculations. It is not suitable to make an accurate judgement on the operating condition of an industrial boiler, especially a wood pellets-fired one. In order to solve this problem, the paper presents a simplified mathematical model to calculate the thermal efficiency of a wood pellets-fired industrial boiler on-line by using an error analysis method. More concretely speaking, first, based on the results of the error analysis of an industrial boiler thermal efficiency, main factors that affect the thermal efficiency of a wood pellets-fired industrial boiler are obtained. Then, a simplified mathematical model to calculate the thermal efficiency of the wood pellets-fired industrial boiler is developed in terms of the major factors. Finally, the calculating results of the industrial boiler thermal efficiency based on the model are compared with the test values given by Guangdong Special Equipment Inspection and Research Institute and the maximum deviation limits within 3\%. Therefore, it can be concluded that the simplified mathematical model proposed in this paper for calculating the thermal efficiency of the wood pellets-fired industrial boiler is proved to be practical, applicable and worth popularizing.
\end{abstract}

Keywords: Thermal Efficiency, Wood Pellets-Fired Industrial Boiler, Simplified Mathematical Model, Error Analysis, Model Verification

\section{Introduction}

Biomass Pellet fuels (or Biomass Pellets) are biofuels made from compressed organic matter or biomass [1]. Biomass Pellets can be made from any one of the five general categories of biomass: industrial wastes and by-products, food wastes, agricultural residues, energy crops, and virgin lumbers [2]. Wood pellets are the most common type of pellet fuel, and are generally made from compacted sawdust [3] and related industrial wastes from the milling of lumber, manufacturing of wood products and furniture or construction. [4]

Because wood pellets have the characteristics of low moisture content (below 10\%) and low ash content (below $5 \%$ ) [5], they have been widely used as fuels in existing industrial boilers [6]. Therefore, how to reduce the fuel-consumption of a wood pellets-fired boiler has become an important issue.

Thermal efficiency is a key technical parameter which indicates the performance of an industrial boiler fueled with wood pellets. The common problems of the industrial boiler combustion, such as incomplete combustion and high carbon content in slags [7-8], can be found through an analysis of 
thermal efficiency. Then, based on the results of the analysis, the boiler's operation could be adjusted in time to maximize its thermal efficiency. Thus, it is necessary to develop a mathematical model for calculating the thermal efficiency of the industrial boiler fueled with wood pellets.

Actually, many researchers have established the mathematical models for calculating the energy efficiency of coal-fired industrial boilers, including ASME PTC4, GB10184 [9] and JIS B 8222 [10] etc. In addition, by using the concept of energy and exergy efficiency, Saidur et al [11] have found that the combustion chamber mainly contributes to the exergy loss in the boiler. Luo Chao et al [12] established a mathematical model for the analysis of thermal efficiency and optimal design for boiler system. The results show that the thermal efficiency of an industrial boiler increases $0.8 \%-1 \%$ when the temperature of exhausted gases increases 10-15 degrees Celsius. J. Bujak [13] has introduced a mathematical model of a boiler room to research its thermal efficiency. The model is regarded as an open thermodynamic system exchanging mass, energy and heat with the atmosphere. He has found that the heat recovery is minimal when the heat load is low $(<=30 \%)$ and the value of heat recovered from outlet exhausted gases in the system with an economizer at full heat power of the boiler fluctuates between $4 \%$ and $7 \%$. Harish Satyavada and Simone Baldi [14] have developed a mathematical model to monitor the energy efficiency of condensing boilers and have pointed out that the thermal efficiency degrades as inlet water temperature increases.

As it has been mentioned earlier, there is a lot of literature about the mathematical models to calculate the thermal efficiency of coal-fired industrial boilers. However, few references can be obtained about the mathematical models of wood pellets-fired industrial boilers. Furthermore, the error analysis of the thermal efficiency of the industrial boiler plays an important role in the establishment of the mathematical model to calculate the thermal efficiency of an industrial boiler because the main factors that affect the thermal efficiency of a coal-fired industrial boiler can be determined by using the method of error analysis $[15,16]$. Based on the results of error analysis, a simple and accurate mathematical model to calculate the thermal efficiency of an industrial boiler could be developed. To the best of the authors' knowledge, however, there is little literature about the error analysis method applied in establishing the mathematical model to calculate the thermal efficiency of a coal-fired industrial boiler, let alone a wood pellets-fired industrial boiler, but this problem will be solved in this paper.

In summary, it can be clearly seen that the works are extremely limited on the investigations of the establishment of the mathematical model to calculate the thermal efficiency of a wood pellets-fired industrial boiler by using error analysis method. Thermal efficiency is an essential parameter dictating the energy-consumption of an industrial boiler. Moreover, the error analysis of the thermal efficiency is a very important approach to establishing the mathematical model to calculate the thermal efficiency of an industrial boiler.

Therefore, in the present study, the main factors that affect the thermal efficiency of an industrial boiler fueled with wood pellets are firstly determined by using the method of error analysis. On this basis, a simple and accurate mathematical model to calculate the thermal efficiency of a wood pellets-fired industrial boiler is acquired through the multiple regression of the main factors. The model is applicable in on-line calculation of the thermal efficiency of a wood pellets-fired boiler and is of great significance to the energy-saving of an industrial boiler.

\section{Method}

The industrial boiler efficiency is the key performance indicator reflecting the operating condition of an industrial boiler and the thermal efficiency of an industrial boiler can be described as follows[17]:

$$
\eta_{\mathrm{gl}}=\mathrm{q}_{1}=100-\sum_{\mathrm{i}=2}^{6} \mathrm{q}_{\mathrm{i}}(\%)
$$

where, $q_{i}(i=2,3, \cdots, 6)$ respectively represents net heat $q_{1}$, heat loss due to exhaust gas $\mathrm{q}_{2}$, heat loss due to unburned gas $\mathrm{q}_{3}$, heat loss due to unburned carbon $\mathrm{q}_{4}$, heat loss due to radiation $\mathrm{q}_{5}$, and heat loss due to sensible heat in slag $\mathrm{q}_{6}$. The following empirical equations can be used to calculate the values of q2, q3, q4, q5 and q6 [18]:

$$
\mathrm{q}_{2}=\left(\mathrm{m}+\mathrm{n} \alpha_{\mathrm{py}}\right)\left(1-\frac{\mathrm{q}_{4}}{100}\right) \frac{\vartheta_{\mathrm{py}}-\mathrm{t}_{\mathrm{amb}}}{100}(\%)
$$

Where $\mathrm{m}=0.5, \mathrm{n}=3.45, \alpha_{\mathrm{py}}$ is the excess air coefficient, $\vartheta_{\mathrm{py}}$ is exhaust gas temperature, ${ }^{\circ} \mathrm{C}, \mathrm{t}_{\mathrm{amb}}$ is the ambient temperature, ${ }^{\circ} \mathrm{C}$.

$$
\mathrm{q}_{3}=\lambda \alpha_{\mathrm{py}} \mathrm{V}_{\mathrm{CO}}(\%)
$$

Where $\alpha_{\mathrm{py}} \approx \frac{0.21}{0.21-\mathrm{V}_{\mathrm{O} 2}}, \lambda=3.2, \mathrm{~V}_{\mathrm{O} 2}(\%)$ is the volume percentage of $\mathrm{O}_{2}$ in exhaust flue gas and $\mathrm{V}_{\mathrm{CO}}(\%)$ is the volume percentage of $\mathrm{CO}$ in exhaust flue gas.

$$
\mathrm{q}_{4}=\frac{\mathrm{BA}_{\mathrm{ar}}}{\mathrm{Q}_{\mathrm{r}}}\left(\frac{\mathrm{a}_{\mathrm{hz}} \mathrm{C}_{\mathrm{hz}}}{100-\mathrm{C}_{\mathrm{hz}}}+\frac{\mathrm{a}_{\mathrm{fh}} \mathrm{C}_{\mathrm{fh}}}{100-\mathrm{C}_{\mathrm{fh}}}\right)
$$

Where, $\mathrm{B}=33700(\mathrm{~kJ} / \mathrm{kg})$, Aar $(\%)$ is the ash content of as received basis in fuel, $Q_{\mathrm{r}}$ is the low calorific value of as received basis $(\mathrm{kJ} / \mathrm{kg}), \mathrm{C}_{\mathrm{hz}}(\%)$ and $\mathrm{C}_{\mathrm{fh}}(\%)$ respectively represent the weight percentage of combustible materials in coal slag and fly ash and $\mathrm{a}_{\mathrm{hz}}$ and $\mathrm{a}_{\mathrm{fh}}$ respectively represent the percentage of coal slag content and fly ash content in total amount of fuel ash. Meanwhile, $\mathrm{a}_{\mathrm{hz}}=0.1, \mathrm{a}_{\mathrm{fh}}=0.9[19$, 20]. In addition:

$$
\mathrm{q}_{5}=\frac{5.82 * 0.62 * X}{\mathrm{X}_{0}}(\%)
$$

Where $\mathrm{X}_{0}$ is the rated load of a boiler, $\mathrm{X}$ is the current load of an industrial boiler. 


$$
\mathrm{q}_{6}=\mathrm{a}_{\mathrm{hz}} \frac{100}{100-\mathrm{C}_{\mathrm{hz}}}(\mathrm{c} \vartheta)_{\mathrm{hz}} \frac{\mathrm{A}_{\mathrm{ar}}}{\mathrm{Q}_{\mathrm{r}}}
$$

Where $(c \vartheta)_{h z}$ is the enthalpy of coal slag [17] and

$$
(\mathrm{c} \vartheta)_{\mathrm{hz}}=0.0002887 \theta_{\mathrm{py}}^{2}+0.6851 \theta_{\mathrm{py}}+26.76
$$

Then, the following equation can be obtained:

$$
\begin{aligned}
\eta_{\mathrm{gl}}=100-\left[\left(\mathrm{m}+\mathrm{n} \alpha_{\mathrm{py}}\right)\left(1-\frac{\mathrm{q}_{4}}{100}\right) \frac{\vartheta_{\mathrm{py}}-\mathrm{t}_{\mathrm{amb}}}{100}+\lambda \alpha_{\mathrm{py}} \mathrm{V}_{\mathrm{CO}}\right. \\
+\frac{\mathrm{BA} \mathrm{ar}}{\mathrm{Q}_{\mathrm{r}}}\left(\frac{\mathrm{a}_{\mathrm{hz}} \mathrm{C}_{\mathrm{hz}}}{100-\mathrm{C}_{\mathrm{hz}}}+\frac{\mathrm{a}_{\mathrm{fh}} \mathrm{C}_{\mathrm{fh}}}{100-\mathrm{C}_{\mathrm{fh}}}\right)+\left(-\frac{\mathrm{hX}}{100 \mathrm{X}_{0}}+\mathrm{d}\right) \\
\left.+\mathrm{a}_{\mathrm{hz}} \frac{100}{100-\mathrm{C}_{\mathrm{hz}}}(\mathrm{c} \vartheta)_{\mathrm{hz}} \frac{\mathrm{A}_{\mathrm{ar}}}{\mathrm{Q}_{\mathrm{r}}}\right](\%)
\end{aligned}
$$

Thus, the following conclusion can be achieved:

$$
\begin{array}{r}
\eta_{\mathrm{gl}}=\mathrm{f}\left(\theta_{\mathrm{py}}, \mathrm{V}_{\mathrm{CO}}, \mathrm{C}_{\mathrm{hz}}, \mathrm{C}_{\mathrm{fh}}, \mathrm{A}_{\mathrm{ar}}, \mathrm{Q}_{\mathrm{r}}, \mathrm{V}_{\mathrm{O}_{2}}\right) \\
=\mathrm{f}\left(\mathrm{X}_{1}, \mathrm{X}_{2}, \mathrm{X}_{3}, \mathrm{X}_{4}, \mathrm{X}_{5}, \mathrm{X}_{6}, \mathrm{X}_{7}\right)
\end{array}
$$

Based on the principle of calculus, the following equation can be acquired:

$$
\begin{gathered}
\Delta \eta_{\mathrm{gl}}=\frac{\partial \eta_{\mathrm{gl}}}{\partial \theta_{\mathrm{py}}} \times \Delta \theta_{\mathrm{py}}+\frac{\partial \eta_{\mathrm{gl}}}{\partial \mathrm{V}_{\mathrm{O}_{2}}} \times \Delta \mathrm{V}_{\mathrm{Co}}+\cdots+\frac{\partial \eta_{\mathrm{gl}}}{\partial \mathrm{Q}_{\mathrm{r}}} \times \Delta \mathrm{V}_{\mathrm{O}_{2}} \\
=\sum_{\mathrm{i}=1}^{7} \mathrm{C}_{\mathrm{i}} \times \Delta \mathrm{X}_{\mathrm{i}}
\end{gathered}
$$

Where, $\Delta \eta_{\mathrm{gl}}$ is the test error of the thermal efficient of a boiler, $\Delta \mathrm{X}_{\mathrm{i}}$ is the measurement error of $\mathrm{X}_{\mathrm{i}},\left|\mathrm{C}_{\mathrm{i}}\right|=\left|\frac{\partial \eta_{\mathrm{gl}}}{\partial \mathrm{X}_{\mathrm{i}}}\right|$ (the absolute value of partial derivative) [18]. What is most interesting to us is the value of $\left|C_{i}\right|$ which reflects the influence of $\mathrm{X}_{\mathrm{i}}$ on $\eta_{\mathrm{gl}}$.

\section{Result}

The calculation results of $\left|C_{i}\right|$ for a $6 t / h$ wood pellets-fired industrial boiler are listed in table 1 .

Table 1. Calculation results of $\left|C_{i}\right|$ for a $6 t / h$ wood pellets-fired industrial boiler.

\begin{tabular}{lllll}
\hline Items & Symbols & Unit & Values & Absolute values of partial derivative $\left(\left|\mathbf{C}_{\mathbf{i}}\right|\right)$ \\
\hline Exhaust flue gas temperature & $\theta_{\mathrm{py}}$ & ${ }^{\circ} \mathrm{C}$ & 173.9 & $0.00435\left(\left|\mathrm{C}_{1}\right|\right)$ \\
CO content in exhaust flue gas & $\mathrm{V}_{\mathrm{CO}}$ & $\%$ & 0.0171 & $0.06005\left(\left|\mathrm{C}_{2}\right|\right)$ \\
Unburned carbon content in slag & $\mathrm{C}_{\mathrm{hz}}$ & $\%$ & 10.48 & $0.00842\left(\left|\mathrm{C}_{3}\right|\right)$ \\
Unburned carbon content in fly ash & $\mathrm{C}_{\mathrm{fh}}$ & $\%$ & 22.37 & $0.03594\left(\left|\mathrm{C}_{4}\right|\right)$ \\
Ash percentage of the received base & $\mathrm{A}_{\mathrm{ar}}$ & $\%$ & 1.41 & $0.26175\left(\left|\mathrm{C}_{5}\right|\right)$ \\
Low calorific value & $\mathrm{Q}_{\mathrm{r}}$ & $\mathrm{kJ} / \mathrm{kg}$ & 16090 & $2.75 \mathrm{E}^{-05}\left(\left|\mathrm{C}_{6}\right|\right)$ \\
Oxygen content in exhaust flue gas & $\mathrm{V}_{\mathrm{O}_{2}}$ & $\%$ & 12.3 & $0.00926\left(\left|\mathrm{C}_{7}\right|\right)$ \\
\hline
\end{tabular}

From the results depicted in table 1 , it can be clearly seen that the minimum absolute value of partial derivative is $\left|\mathrm{C}_{6}\right|$ which equals $2.73395 \mathrm{E}^{-05}$. Further, the values of $\left(\left|\mathrm{C}_{\mathrm{i}}\right|\right)$ are shown in figure-1.

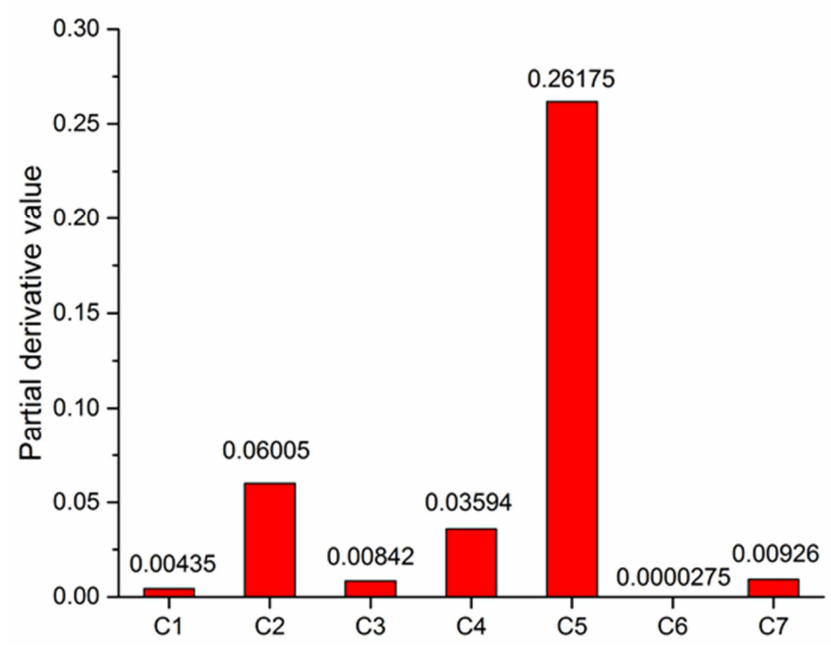

Figure 1. Values of partial derivative $\left(\left|C_{i}\right|\right)$.

From figure-1, it can be clearly seen that the effect of $\left|\mathrm{C}_{6}\right|$ is very small, and hence the effect of $Q_{r}$ on $\eta_{\mathrm{gl}}$ can be ignored. Therefore, the following equation can be obtained: $\eta_{\mathrm{gl}}=\mathrm{f}\left(\theta_{\mathrm{py}}, \mathrm{V}_{\mathrm{CO}}, \mathrm{C}_{\mathrm{hz}}, \mathrm{C}_{\mathrm{fh}}, \mathrm{A}_{\mathrm{ar}}, \mathrm{V}_{\mathrm{O}_{2}}\right)=\mathrm{f}\left(\mathrm{Y}_{1}, \mathrm{Y}_{2}, \mathrm{Y}_{3}, \mathrm{Y}_{4}, \mathrm{Y}_{5}, \mathrm{Y}_{6}\right)$

It means that $\eta_{\mathrm{gl}}$ can be expressed as a function of $\theta_{\mathrm{py}}, \mathrm{V}_{\mathrm{CO}}, \mathrm{C}_{\mathrm{hz}}, \mathrm{C}_{\mathrm{fh}}, \mathrm{A}_{\mathrm{ar}}$ and $\mathrm{V}_{\mathrm{O}_{2}}$. In order to establish a corresponding mathematical model, a multiple linear regression analysis has been carried out and the resulting models are discussed below.

\section{Discussion}

Based on a number of the test values of the thermal efficiency of pellets-fired industrial boilers, the following empirical equation to calculate the thermal efficiency $\left(\eta_{\mathrm{gl}}\right)$ is obtained by using a multiple linear regression method [21]:

$$
\begin{gathered}
\eta_{\mathrm{gl}}=-0.06035 \mathrm{Y}_{1}+90.666 \mathrm{Y}_{2}+0.00103 \mathrm{Y}_{3}+0.1438 \mathrm{Y}_{4}- \\
0.2433 \mathrm{Y}_{5}-0.8168 \mathrm{Y}_{6}+98.588
\end{gathered}
$$

Figure-2 shows a relationship between the actual and predicted values of the thermal efficiency, which indicates that the thermal efficiency model is adequate accurate because the residuals lie close to the diagonal line. 


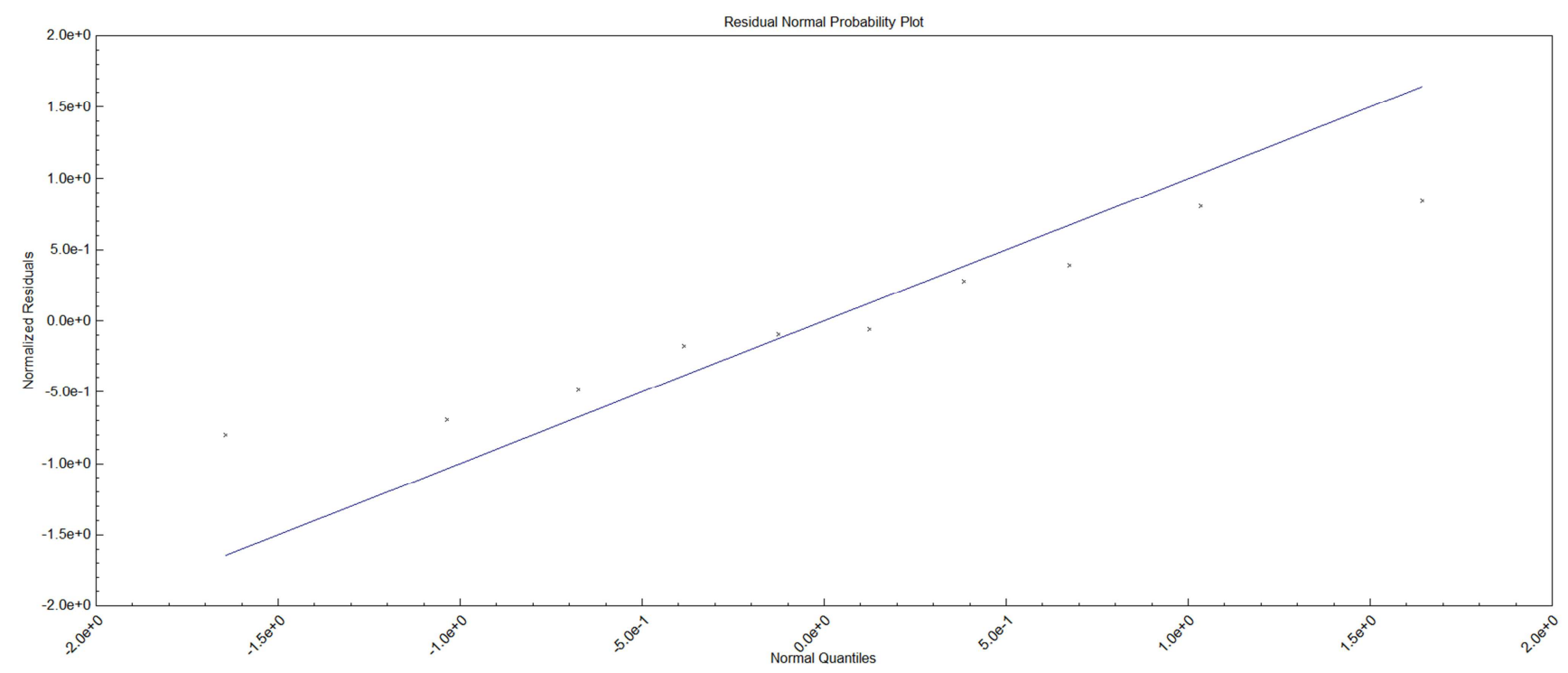

Figure 2. Graph of the predicted versus actual values of the thermal efficiency of pellets-fired industrial boilers.

In order to further quantitatively analyze the correctness of the above mathematical model, the values of the thermal efficiency of ten pellets-fired industrial boilers obtained from test reports are compared with the values calculated by using the empirical equation. The relative deviations between test values and predicted values are shown in table 2 . It should be noted that the relative deviation is equal to |test value predicted value| / test value.

Table 2. Relative deviations between test values and predicted values for the thermal efficiency of wood pellets-fired industrial boilers.

\begin{tabular}{|c|c|c|c|c|c|c|c|c|}
\hline $\mathbf{Y}_{1}\left({ }^{\circ} \mathrm{C}\right)$ & $Y_{2}(\%)$ & $\mathbf{Y}_{3}(\%)$ & $Y_{4}(\%)$ & $Y_{5}(\%)$ & $Y_{6}(\%)$ & Test values & $\begin{array}{l}\text { Predicted } \\
\text { values }\end{array}$ & $\begin{array}{l}\text { Relative } \\
\text { deviations }\end{array}$ \\
\hline 183.8 & 0.0205 & 8.62 & 11.75 & 1.69 & 11.40 & 82.37 & 81.41 & $1.17 \%$ \\
\hline 217.3 & 0.0243 & 13.80 & 19.31 & 1.27 & 8.70 & 82.27 & 83.49 & $1.48 \%$ \\
\hline 220.4 & 0.0127 & 10.48 & 21.82 & 1.62 & 8.70 & 82.63 & 82.18 & $0.54 \%$ \\
\hline 139.7 & 0.0242 & 28.00 & 18.67 & 1.88 & 11.39 & 85.88 & 85.56 & $0.37 \%$ \\
\hline 172.9 & 0.0060 & 3.68 & 9.57 & 1.43 & 14.80 & 76.88 & 77.67 & $1.03 \%$ \\
\hline 180.3 & 0.0109 & 3.16 & 3.39 & 4.87 & 14.30 & 76.28 & 76.35 & $0.09 \%$ \\
\hline 156.8 & 0.0135 & 22.89 & 26.86 & 1.77 & 11.53 & 84.04 & 84.60 & $0.67 \%$ \\
\hline 173.9 & 0.0122 & 10.48 & 22.37 & 1.41 & 12.30 & 83.05 & 82.13 & $1.10 \%$ \\
\hline 144.8 & 0.0420 & 9.22 & 17.02 & 1.98 & 7.80 & 89.14 & 89.35 & $0.24 \%$ \\
\hline 136.0 & 0.0045 & 10.44 & 33.62 & 2.03 & 9.90 & 87.04 & 87.15 & $0.13 \%$ \\
\hline
\end{tabular}

It can be clearly seen from table 2 that the test values and the calculated values match really well and the maximum relative deviation between them limits within $1.5 \%$. Therefore, this empirical equation with high degree of credibility can be widely applied. This will greatly reduce the workload of an industrial boiler testing, which is of great significance.

\section{Conclusion}

Based on the results of the error analysis of the thermal efficiency, we can safely say that the value of $Q_{r}$ (low calorific value) of the fuel has little impact on the thermal efficiency of the pellets-fired industrial boiler, and hence $\eta_{\mathrm{gl}}$ (thermal efficiency) can be expressed as a function of $\theta_{\mathrm{py}}, \mathrm{V}_{\mathrm{Co}}, \mathrm{C}_{\mathrm{hz}}, \mathrm{C}_{\mathrm{fh}}, \mathrm{A}_{\mathrm{ar}}$ and $\mathrm{V}_{\mathrm{O}_{2}}$. In addition, on the basis of multiple linear regression, an empirical equation to calculate the thermal efficiency $\left(\eta_{\mathrm{gl}}\right)$ of the wood pellets-fired industrial boiler can be reached:

$$
\begin{gathered}
\eta_{\mathrm{gl}}=-0.06035 \mathrm{Y}_{1}+90.666 \mathrm{Y}_{2}+0.00103 \mathrm{Y}_{3}+0.1438 \mathrm{Y}_{4}- \\
0.2433 \mathrm{Y}_{5}-0.8168 \mathrm{Y}_{6}+98.588
\end{gathered}
$$

The credibility of this formula is verified because the maximum deviation between test values and calculated values is confined within $1.5 \%$. Therefore, it can be said that the simplified mathematical model proposed in this paper for calculating the thermal efficiency of the wood pellets-fired industrial boiler is adequate and accurate. Also, based on the comparisons between predicted and test values of the thermal efficiency of boilers, this model is proved to be practical, applicable and worth popularizing.

\section{References}

[1] "Biomass Energy". Alternate Energy. Retrieved 16 February 2015.

[2] "Sources of biomass". BIOMASS Energy Centre. Retrieved 16 February2015. 
[3] "Use EFB Pellet as Renewable Energy". Biofuel Resource. Retrieved16 February 2015.

[4] Wood Pellets from PKS \& Coconut Shell. "Wood Pellets from PKS and Coconut Shell". Retrieved 13 January 2013.

[5] Alakangas, Eija (18 November 2009). "European pellet standards". Retrieved 16 February 2015.

[6] Cardellichio, P.; et al. (2010). "Massachusetts Biomass Sustainability and Carbon Policy Study: Report to the Commonwealth of Massachusetts Department of Energy Resources"(PDF). Natural Capital Initiative Report NCI-2010-03. Brunswick, Maine: Manomet Center for Conservation Sciences. Retrieved 2014-03-14.

[7] Wang Baowei, Qu Yuhua. Discussion on the boiler measures for saving coals from boiler [J]. Boiler Manufacturing, 1999(1):65-70.

[8] Liang Xin, Wang Naiji. The joint control status of pulverized coal industry boiler and pollutants [J]. District Heating, 2014(6):52-58

[9] Ministry of Machine Building and Electronic Industry of PRC, GB10184--1988 performance test code of utility boiler[S], In Chinese, 1988

[10] Japanese standards association, JIS B 8222-1993 Land boiler-heat balancing, 1993

[11] Saidur R, Ahamed J U, Masjuki H H. Energy, exergy and economic analysis of industrial boilers [J]. Energy Policy, 2010, 38(5):2188-2197.

[12] Luo Chao et al, The Effect Analysis of Thermal Efficiency and Optimal Design for Boiler System, The 8th International Conference on Applied Energy - ICAE2016.
[13] J. Bujak, Mathematical modelling of a steam boiler room to research thermal efficiency, Energy 33 (2008) 1779-1787.

[14] Harish Satyavada, Simone Baldi, Monitoring energy efficiency of condensing boilers via hybrid firstprinciple modelling and estimation, Energy 142 (2018) 121-129.

[15] Robert Junga et al, Uncertainty estimation of the efficiency of small-scale boilers, Measurement 97 (2017) 186-194.

[16] ZHUO Xunjia et al, ANALYSIS AND APPLICATION OF UNCERTAINTY IN ANTI-BALANCING THERMAL EFFICIENCY oF BoILERS, thermal power generation 1002-3364 (2012) 02-0032-05.

[17] J. Wu, Y. Zhang, G. Xu, Y. Lin and X. Lv (2014) Research on the Optimization of Boiler Efficiency based on Artificial Bee Colony Algorithm, Computer and Information Science, 7, 30-38.

[18] Z. Xunjia, L. Jingyan, W. Jiangwei and J. Lincan (2012) Analysis and Application of Uncertainty in Anti-Balancing Thermal Efficiency of Boilers, Thermal Power Generation, 2, 32-36.

[19] P. Basu (2000) Boiler and burners, Springer, New York, USA, $11,320-9$.

[20] L. Li (2017) Hot test report of a 220t/h CFB boiler after retrofit, Guang Dong Special Equipment Test and Research Institute, Guangdong University of Technology, Guangzhou, China.

[21] Ren LQ. Test optimization techniques. 1st ed. Beijing: Machinery Industry Press of China; 1987. 